\title{
Brote de rabia urbana transmitida por perros en el distrito de Santa Marta, Colombia, 2006-2008
}

\author{
Andrés Páez ${ }^{1,2}$, Gloria Rey ${ }^{1}$, Carlos Agudelo ${ }^{1}$, Álvaro Dulce ${ }^{3}$, Edgar Parra ${ }^{4}$, \\ Hernando Díaz-Granados ${ }^{5}$, Damaris Heredia ${ }^{3}$, Luis Polo ${ }^{3}$ \\ 1 Laboratorio de Virología, Instituto Nacional de Salud, Bogotá, D.C., Colombia \\ 2 Departamento de Ciencias Básicas, Universidad de La Salle, Bogotá, D.C., Colombia \\ ${ }^{3}$ Subdirección de Vigilancia y Control en Salud Pública, Instituto Nacional de Salud, Bogotá, D.C., \\ Colombia \\ ${ }^{4}$ Laboratorio de Patología, Instituto Nacional de Salud, Bogotá, D.C., Colombia \\ ${ }^{5}$ Secretaría de Salud del Distrito de Santa Marta, Santa Marta, Colombia \\ Instituciones donde se realizó el estudio: \\ Instituto Nacional de Salud, Bogotá, D.C., y Secretaría de Salud de Santa Marta, Santa Marta, Colombia
}

Introducción. En el distrito de Santa Marta ocurrió un brote de rabia urbana entre abril de 2006 y enero de 2008, con cuatro casos fatales en humanos y 28 en perros.

Objetivos. Describir el brote, las técnicas de diagnóstico de laboratorio y las acciones de control de foco empleadas. Medir el impacto de la vacunación antirrábica canina en términos de seroconversión de anticuerpos neutralizantes. Discutir el significado epidemiológico y las implicaciones en salud pública.

Materiales y métodos. Los casos se diagnosticaron por inmunofluorescencia directa, prueba biológica en ratón e inmunohistoquímica. La tipificación viral se hizo por inmunofluorescencia indirecta. Las acciones de control consistieron en un censo canino, vacunación y tratamientos antirrábicos a la población expuesta, vacunación canina y felina, y educación comunitaria. La seroconversión fue investigada por medio de la prueba ELISA de captura.

Resultados. La variante antigénica 1 se caracterizó en todos los casos. Se observó seropositividad en $77 \%$ de los perros vacunados y protección serológica contra la rabia, en $47 \%$. No se observaron diferencias de la respuesta humoral entre sexos de los perros, pero sí existieron diferencias de los porcentajes de perros protegidos entre las comunas del distrito.

Conclusiones. Este brote de rabia ha sido el de mayor magnitud en una ciudad colombiana, según los datos oficiales. Fue causado por perros, lo cual reitera la amenaza que aún representa la rabia urbana para la salud pública, a pesar de la existencia de vacunas eficientes.

El control del brote se logró 20 meses después del primer caso en perros y 14 meses después de haberse iniciado la primera vacunación masiva en animales. Es necesario implementar y mantener acciones para el control de la rabia urbana y evitar su impacto en los humanos.

Palabras clave: rabia, virus de la rabia, Lyssavirus, zoonosis, vigilancia epidemiológica, Colombia.

Outbreak of urban rabies transmitted by dogs in Santa Marta, northern Colombia.

Introduction. An urban rabies outbreak occurred in the District of Santa Marta between April 2006 and January 2008, which resulted in the deaths of 4 humans and 28 dogs.

Objectives. Three objectives were entertained—first, the diagnostic laboratory techniques were described as well as the rabies control actions taken; second, the impact of anti-rabies dog vaccination was assessed in terms of neutralizing antibody seroconversion; and third, the epidemiological significance and public health implications of the outbreak were examined.

Materials and methods. Rabies diagnosis was achieved by direct immunofluorescence, inoculation of mice and immunohistochemistry. Typing of the virus was achieved by indirect immunofluorescence. Control activities included a dog population census, vaccination and treatments for persons exposed to rabies, mass vaccination of dogs and cats, and initiation of a community education program. Seroconversion was investigated by capture ELISA.

Results. Antigenic variant 1 was detected in all cases. Of vaccinated dogs, $77 \%$ were seropositive, 
and $47 \%$ were seroprotected against rabies. No differences were found in the humoral response between dog gender; however significant differences in dog seroprotection were discovered between localized comunities in Santa Marta.

Conclusions. The 2006-2008 urban rabies outbreak was the largest reported in a city in Colombia. It was caused by rabid dogs, and demonstrated that these animals are still a threat for human health despite the existence of efficient rabies vaccines. The control of the outbreak was achieved 20 months after the first rabies case in dogs, and 14 months after the initiation of the first mass vaccination of animals. The necessity of implementation and maintenance of rabies control strategies is underlined for minimizing human risk.

Key words: rabies, rabies virus, Lyssavirus, zoonoses, epidemiologic surveillance, Colombia.

La rabia es una zoonosis causada por virus neurotrópicos del género Lyssavirus, familia Rhabdoviridae, orden Mononegavirales (1). El virión rábico contiene $\mathrm{ARN}$ de cadena sencilla y sentido negativo no segmentado, y codifica cinco proteínas estructurales $(2,3)$.

La rabia es una enfermedad terminal, principalmente de animales; en humanos es un reflejo del grado de contacto con animales infectados. La infección con el virus rábico ocurre en dos formas epidemiológicas diferentes: a) la rabia urbana, con el perro como principal reservorio $y$ transmisor de la enfermedad a los humanos, y b) la rabia silvestre, con especies de los órdenes Carnívora y Quiróptera como principales reservorios y transmisores de la enfermedad, y especies depredadoras como los felinos que actúan como transmisores, principalmente a humanos. Eventualmente, puede ocurrir la transmisión de la rabia entre los dos ciclos epidemiológicos (4-11), lo que resalta el riesgo que presenta para los humanos la enfermedad en cualquier especie animal.

La rabia es endémica en sus dos formas epidemiológicas en la mayoría de países latinoamericanos, incluida Colombia. Actualmente, la transmisión del virus de la rabia representa una gran amenaza para la salud de la población colombiana. Durante el periodo 1992-2008, se registraron en el país 69 casos fatales de rabia en humanos y 1.107 en perros (Datos sin publicar.

\section{Correspondencia:}

Andrés Páez, Laboratorio de Virología, Instituto Nacional de Salud, Avenida Calle 26 № 51-20, CAN, Bogota, D.C., Colombia.

Telefax: (571) 2200928

apaezm@ins.gov.co

Recibido: 22/10/08; aceptado:06/04/09
Laboratorio de Rabia, Grupo de Virología, Instituto Nacional de Salud, Bogotá, D.C.). El 95\% de estos casos se concentraron en tres regiones del país y el $5 \%$ restante se distribuyeron como casos aislados en 15 departamentos de diversas partes del país (12-17).

Las tres regiones mencionadas son: en la región central, el altiplano cundiboyacense (departamentos de Boyacá y Cundinamarca), en la región oriental, el departamento de Arauca $y$, en la región Caribe, los departamentos de Atlántico, Bolívar, Cesar, Córdoba, Magdalena y Sucre. La transmisión del virus de la rabia urbana en el altiplano cundiboyacense y en Arauca se controló con vacunación (último caso confirmado en abril de 2007), mientras que en la región Caribe sigue siendo un grave problema de salud pública, específicamente en el departamento del Magdalena.

Desde abril de 2006 y con el último caso a finales de enero de 2008, se confirmó la presentación de un brote de rabia urbana transmitida por perros en el distrito de Santa Marta, Colombia, con un registro de 4 humanos y 28 perros muertos (figura 1) (cuadro 1), según los datos oficiales del Ministerio de la Protección Social de Colombia (18). En el presente artículo se describe en detalle el brote, las técnicas diagnósticas utilizadas, los procedimientos para la tipificación viral y las acciones realizadas de control de foco.

\section{Materiales y métodos}

\section{Descripción sociocultural y geográfica de las zonas de riesgo}

Se hicieron visitas e inspecciones a las zonas en donde ocurrieron los casos fatales de rabia 

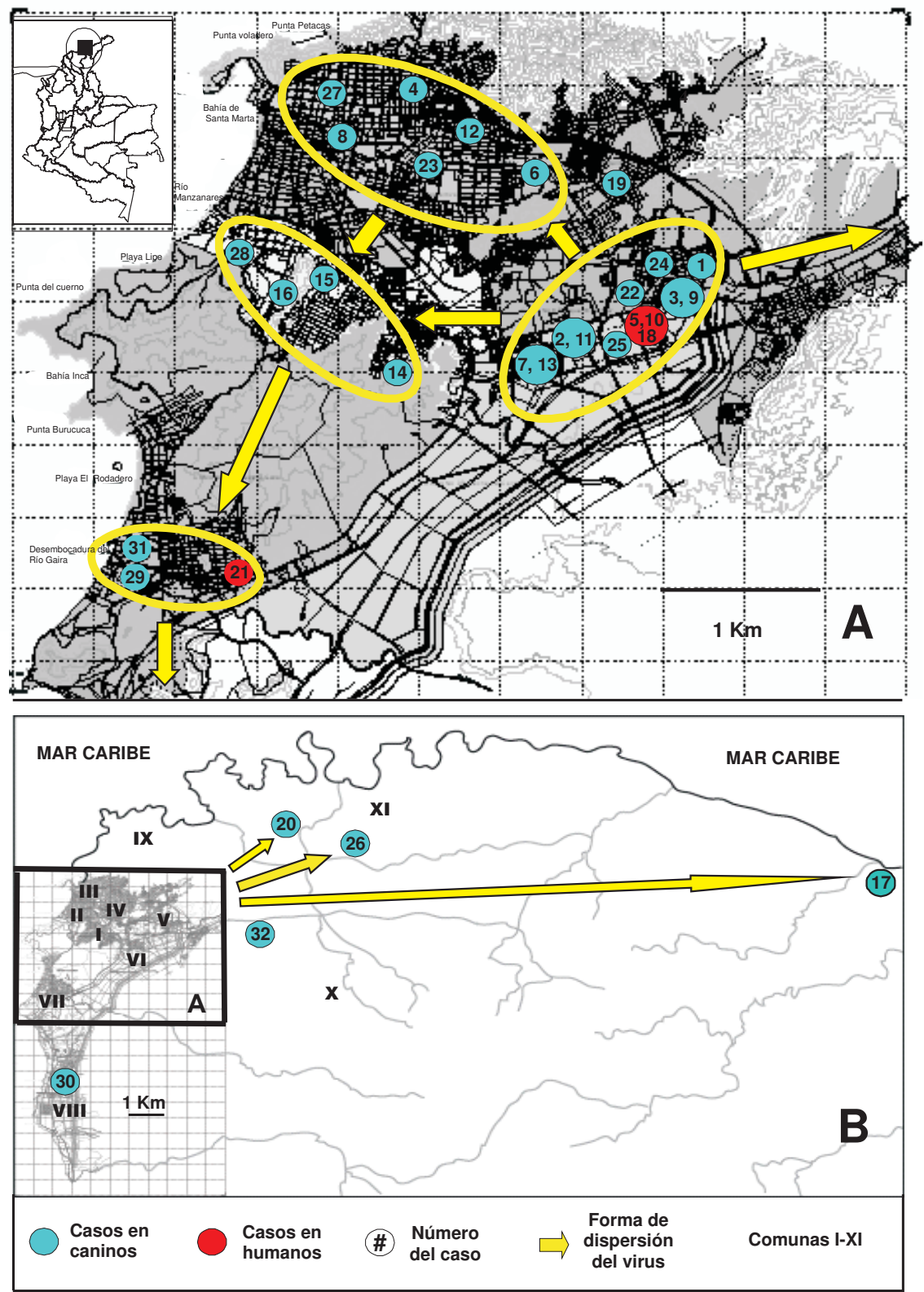

Figura 1. Ubicación y dinámica de dispersión de los casos de rabia en el distrito de Santa Marta, Colombia, 2006-2008. Mapas urbano (A) y rural (B) del distrito de Santa Marta, Colombia, donde se muestra la localización geográfica de los casos de rabia en humanos (puntos rojos) y perros (puntos azules). Los números dentro de los círculos corresponden al número de los casos según el cuadro 1. Las áreas encerradas y las flechas amarillas muestran la manera cómo se dispersó la transmisión viral. Los números romanos corresponden a las comunas del distrito.

en humanos y perros. Dichas visitas tuvieron dos objetivos principales: primero, la investigación de campo y el estudio epidemiológico por medio de la descripción de las zonas y de las comunidades afectadas por la transmisión del virus de la rabia y la toma de testimonios de amigos y familiares de las víctimas humanas: segundo, la caracterización y control del foco por medio de la vacunación de perros y humanos que hubiesen tenido contacto con casos positivos, y 
Cuadro 1. Casos confirmados de rabia en perros y humanos en Santa Marta 2006-2008.

\begin{tabular}{|c|c|c|c|c|c|}
\hline Caso & Especie & $\begin{array}{c}\text { Fecha de } \\
\text { muerte }\end{array}$ & $\begin{array}{c}\text { Semana } \\
\text { epidemiológica }\end{array}$ & $\begin{array}{c}\text { Método } \\
\text { diagnóstico }\end{array}$ & $\begin{array}{l}\text { Variante } \\
\text { antigénica }\end{array}$ \\
\hline 1 & Canina & $17-04-06$ & 16 & IFD - PB & 1 \\
\hline 2 & Canina & 15- 06-06 & 24 & IFD - PB & 1 \\
\hline 3 & Canina & ${ }^{a}(\ldots)$ & $\mathrm{a}(\ldots)$ & ${ }^{\mathrm{b}} \mathrm{Nexo}$ & $\mathrm{a}(\ldots)$ \\
\hline 4 & Canina & $12-10-06$ & 41 & IFD - PB & 1 \\
\hline 5 & Humana & 07-11-06 & 45 & $\mathrm{IHQ}$ & $\mathrm{a}(\ldots)$ \\
\hline 6 & Canina & $16-11-06$ & 46 & IFD - PB & 1 \\
\hline 7 & Canina & $16-11-06$ & 46 & IFD - PB & 1 \\
\hline 8 & Canina & $17-11-06$ & 46 & IFD - PB & 1 \\
\hline 9 & Canina & 20-11-06 & 46 & IFD - PB & 1 \\
\hline 10 & Humana & $25-11-06$ & 47 & IHQ - IFD - PB & 1 \\
\hline 11 & Canina & $02-12-06$ & 48 & IFD - PB & 1 \\
\hline 12 & Canina & $04-12-06$ & 49 & IFD - PB & 1 \\
\hline 13 & Canina & $08-12-06$ & 49 & IFD - PB & 1 \\
\hline 14 & Canina & $10-12-06$ & 50 & IFD - PB & 1 \\
\hline 15 & Canina & $11-12-06$ & 50 & IFD - PB & 1 \\
\hline 16 & Canina & $30-12-06$ & 52 & IFD - PB & 1 \\
\hline 17 & Canina & $12-01-07$ & 2 & IFD - PB & 1 \\
\hline 18 & Humana & $16-01-07$ & 3 & $I H Q-I F D-P B$ & 1 \\
\hline 19 & Canina & $16-01-07$ & 3 & IFD - PB & 1 \\
\hline 20 & Canina & $23-01.07$ & 4 & IFD - PB & 1 \\
\hline 21 & Humana & $27-01-07$ & 4 & $\mathrm{IHQ}-\mathrm{IFD}-\mathrm{PB}$ & 1 \\
\hline 22 & Canina & $31-01-07$ & 5 & IFD - PB & 1 \\
\hline 23 & Canina & $06-02-07$ & 6 & IFD - PB & 1 \\
\hline 24 & Canina & $13-02-07$ & 7 & IFD - PB & 1 \\
\hline 25 & Canina & $13-02-07$ & 7 & IFD - PB & 1 \\
\hline 26 & Canina & $24-02-07$ & 8 & IFD - PB & 1 \\
\hline 27 & Canina & 07-03-07 & 10 & IFD - PB & 1 \\
\hline 28 & Canina & 03-05-07 & 18 & IFD - PB & 1 \\
\hline 29 & Canina & $22-05-07$ & 21 & IFD - PB & 1 \\
\hline 30 & Canina & $30-09-07$ & 40 & IFD - PB & 1 \\
\hline 31 & Canina & $27-10-07$ & 43 & IFD - PB & 1 \\
\hline 32 & Canina & $28-01-08$ & 5 & IFD - PB & 1 \\
\hline
\end{tabular}

a $(. .$.$) : no determinado.$

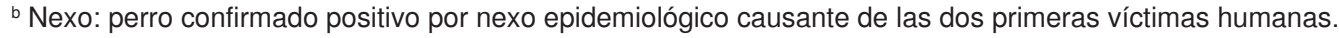

IFD: inmunofluorescencia directa; PB: prueba biológica: IHQ: inmunohistoquímica

las estrategias de información y educación a la comunidad.

\section{Descripción de los casos de rabia en humanos}

La descripción de los casos de rabia en humanos se obtuvo mediante visita al lugar de residencia de las personas infectadas y la toma de los testimonios de familiares y vecinos. Para la descripción de cada caso se tuvo en cuenta la edad, el sexo, la ubicación anatómica y el grado de la exposición rábica, las fechas de inicio de síntomas y la muerte. Además, en los hospitales y centros de salud se obtuvo la información de la sintomatología e historia clínica de los pacientes.

\section{Diagnóstico y tipificación antigénica del virus de la rabia}

El diagnóstico de los casos probables de rabia se llevó a cabo en los Laboratorios de Virología y Patología del Instituto Nacional de Salud en Bogotá. Las técnicas utilizadas fueron las de inmunofluorescencia directa (IFD) sobre material encefálico fresco $(19,20)$, en la cual los anticuerpos policlonales antirrábicos marcados con fluoresceína reconocen el antígeno viral presente en dicho material y se produce una 
señal visible al microscopio de fluorescencia. Para el anterior procedimiento, se utilizó el conjugado antirrábico Rabies DFA Reagent (Light Diagnostics, Cat. № 5100), de acuerdo con las especificaciones del fabricante.

Además, se emplearon las técnicas de histopatología convencional e inmunohistoquímica, utilizando avidina-biotina conjugada con peroxidasa sobre material encefálico fijado en formol neutro al 10\%; el anticuerpo primario policlonal se empleó con dilución 1:160 (21). La prueba confirmatoria se hizo por inoculación intracerebral de la suspensión de cerebro en ratones de laboratorio cepa ICR (Institute of Cancer Research) (22).

La tipificación antigénica del virus se realizó por inmunofluorescencia indirecta utilizando material encefálico infectado con los virus rábicos de cada caso, un panel de ocho anticuerpos monoclonales producidos en ratón de los Centers for Disease Control and Prevention, en Atlanta, Estados Unidos (23), y un anticuerpo secundario IgG anti-ratón producido en cabra conjugado con fluoresceína (Sigma 065H-8874). El patrón general de reactividad (reacción positiva 0 negativa) de los ocho anticuerpos monoclonales, en conjunto, arroja como resultado la variante antigénica de los virus aislados en cada uno de los casos.

\section{Vacunación en perros}

La vacunación se hizo casa a casa en todo el distrito de Santa Marta, previo consentimiento de los propietarios de los animales. El método de vacunación fue por inoculación subcutánea en la parte alta del cuello de los animales. Se utilizó la vacuna antirrábica producida en la línea celular VERO por la Empresa Colombiana de Productos Veterinarias, S.A., lotes RAB165 y RAB167. Se realizaron jornadas masivas de vacunación entre noviembre de 2006 y febrero de 2007, y, posteriormente, en octubre de 2007, así como programas continuos de vacunación dirigidos a inmunizar cachorros mayores de tres meses de edad (figura 2).

Medición del nivel de anticuerpos antirrábicos neutralizantes en los perros vacunados

Después de haber pasado un periodo de entre cuatro y seis meses después de la vacunación masiva de perros, se hizo la toma de sangre de una muestra de 252 perros (147 machos y 105

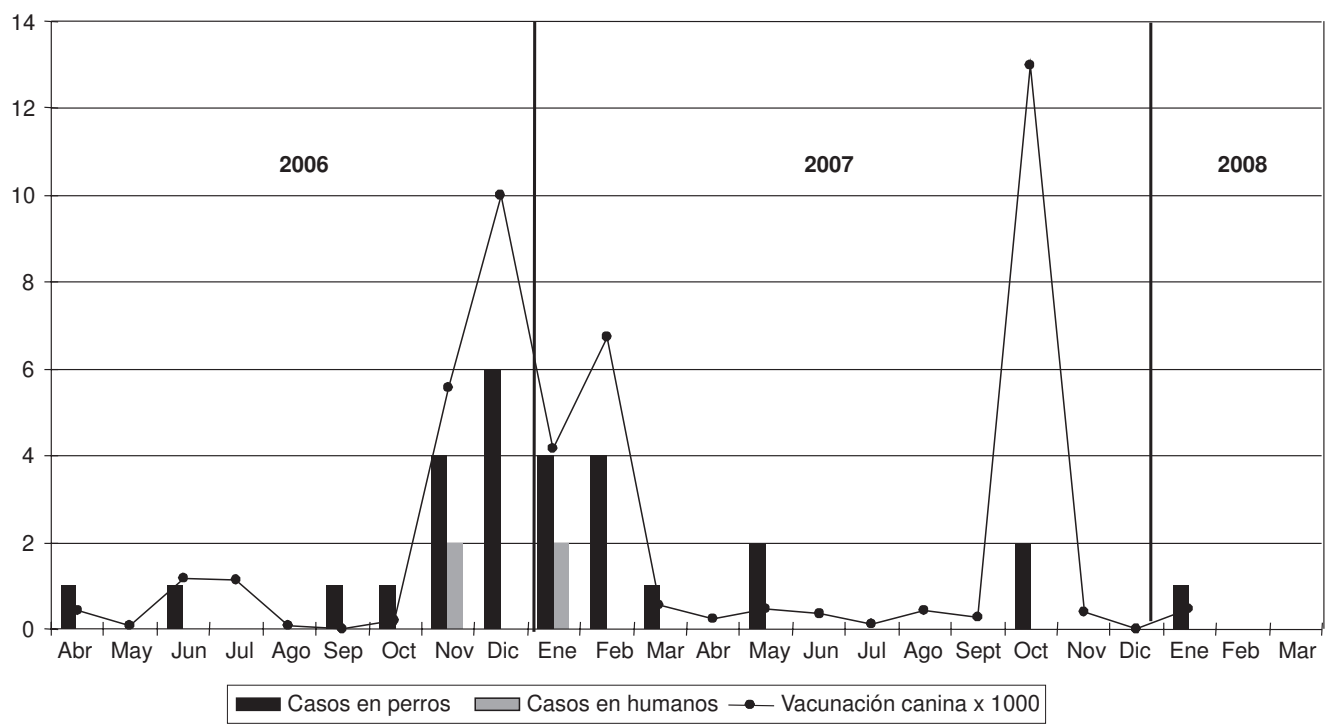

Figura 2. Cronología de casos de rabia en perros y humanos, y de la vacunación canina en el distrito de Santa Marta, Colombia, 2006-2008. Diagrama de barras que muestra cronológicamente la secuencia de casos de rabia en perros y en humanos, además del número de perros vacunados por mes en el distrito de Santa Marta, Colombia, 2006-2008 (marzo). El total de perros según censo de 2007 es de 25.925. 
hembras) con edades entre 1 y 13 años, que habían sido vacunados en las 11 comunas de la ciudad.

El tamaño de la muestra se calculó según la fórmula de Wayne-Daniel, con lo cual se obtuvo una población a muestrear de 224 perros:

$$
\begin{aligned}
& n=N \times Z^{2} \times p \times(1-p) \\
& d^{2}(N-1)+Z^{2} p(1-p)
\end{aligned}
$$

donde, N es la población total, 49.222; Z, el valor correspondiente al nivel de confianza, 95\%; $d$, la precisión absoluta, 3\%, y p el porcentaje de pérdida de muestras, $10 \%$.

Para tomar la muestra se realizó punción de la vena cefálica y se extrajeron 5 a $7 \mathrm{ml}$ de sangre en tubos vacutainer. Las muestras se centrifugaron por 15 minutos a $5.000 \mathrm{~g}$. Los sueros se separaron y almacenaron a -20 grados centígrados hasta el momento de la medición del nivel de anticuerpos antirrábicos neutralizantes, lo cual se hizo por ELISA utilizando el estuche Platelia Rabia (Bio-Rad, Cat № 357-2200, Lote CH-B:4E0181), siguiendo la metodología y precauciones que recomienda el fabricante.

\section{Vacunación en humanos}

Se realizaron tratamientos de vacunación antirrábica posterior a la exposición en las personas que habían sufrido agresiones por animales, principalmente perros y gatos, al igual que en las que estuvieron en contacto con los humanos con diagnóstico positivo, tales como familiares, amigos y personal médico, según el grado de exposición. Dichos tratamientos consistieron en cinco dosis intramusculares en el músculo deltoides, acompañadas de la aplicación de suero antirrábico, siguiendo las recomendaciones del "Protocolo y guía de atención a pacientes agredidos" del Ministerio de la Protección Social de Colombia (24). La vacuna antirrábica utilizada fue Verorab ${ }^{\circledR}$ (Sanofi Pasteur), lote 21158-1- exp. 11/12/08.

\section{Control de transmisores y reservorios}

Se eliminaron los perros sin dueño que deambulaban por el distrito de Santa Marta y que representaban una potencial amenaza para la salud pública. El procedimiento de eliminación consistió en la inoculación de una dosis de fenilhidantoína y pentobarbital sódico en la vena safena. El número de perros eliminados entre 2006 y 2007 por mes, se muestra en el cuadro 2.

\section{Educación de la comunidad}

Se llevaron a cabo reuniones del Comité Departamental y Distrital de Zoonosis y de los Comités de Vigilancia Epidemiológica, para establecer compromisos y actividades. Se hizo capacitación y actualización en rabia del recurso humano involucrado en la prestación de servicios de salud, como médicos y enfermeras, en instituciones prestadoras de salud del distrito. Se sostuvieron reuniones con líderes comunitarios y capacitaciones de promoción, prevención y control de la rabia de los Comités de Participación y Vigilancia Comunitarias, así como de estudiantes en instituciones de educación secundaria y de medicina y enfermería de los establecimientos de educación superior de Santa Marta. Se difundió a la comunidad información sobre la rabia, mediante comunicados de prensa, programas radiales y elaboración de volantes plegables.

\section{Análisis estadístico de la información}

Se creó una base de datos en Office Excel XP, para llevar el registro del proceso de vacunación de cada paciente en tiempo real. Los datos se analizaron con el programa SPSS, versión 13,0, con análisis de diferencia de medias y regresión logística, utilizando pruebas post hoc-Scheffé (25), Kolmogorov-Smirnov $(26,27)$ y U de MannWhitney (28).

\section{Resultados}

\section{Descripción sociocultural y geográfica de las zonas de riesgo}

El distrito de Santa Marta está ubicado en la costa norte de Colombia; posee una población de 483.000 habitantes, aproximadamente, y se encuentra dividido en 11 comunas, 8 de las cuales son urbanas (comunas 1 a 8 ) y 3 son rurales (comunas 9 a 11). El distrito es la ciudad capital del departamento de Magdalena.

Los casos de rabia en perros y humanos ocurrieron en todas las comunas urbanas. 
Aunque existen diferencias sociodemográficas y culturales significativas dentro de cada una de las mencionadas comunas y entre éstas, se destaca el hecho de que la mayoría de los casos de rabia se presentaron en las zonas más deprimidas, las cuales se caracterizan por deficiencias en la prestación de servicios públicos, ausencia de alcantarillado y de sistemas adecuados de disposición y recolección de basuras, vías públicas sin pavimentar, alta densidad de población canina, inadecuada tenencia de mascotas, hacinamiento humano, analfabetismo y bajo nivel de vida de los pobladores.

El brote objeto de estudio en el presente artículo tuvo sus primeros casos en perros y en humanos en el barrio Once de Noviembre de la comuna 6 (figura 1). Esta zona es una de las

Cuadro 2. Vacunación antirrábica canina y felina, y eliminación de caninos en el distrito de Santa Marta 2005-2008 (enero).

\begin{tabular}{|c|c|c|c|c|c|}
\hline Fecha & $\begin{array}{c}\text { Perros } \\
\text { vacunados }\end{array}$ & $\begin{array}{l}\text { (\%) Cobertura } \\
\text { vacunación } \\
\text { canina anual }\end{array}$ & $\begin{array}{c}\text { Perros } \\
\text { eliminados }\end{array}$ & $\begin{array}{c}\text { Gatos } \\
\text { vacunados }\end{array}$ & $\begin{array}{l}\text { (\%) Cobertura } \\
\text { vacunación } \\
\text { felina anual }\end{array}$ \\
\hline Enero & 159 & $\mathrm{a}(\ldots)$ & 0 & 1 & $\mathrm{a}(\ldots)$ \\
\hline Febrero & 191 & $a(\ldots)$ & 2 & 17 & $\mathrm{a}(\ldots)$ \\
\hline Marzo & 139 & $a(\ldots)$ & 3 & 12 & $\mathrm{a}(\ldots)$ \\
\hline Abril & 1 & $a(\ldots)$ & 0 & 0 & $\mathrm{a}(\ldots)$ \\
\hline Mayo & 26 & $a(\ldots)$ & 1 & 2 & $a(\ldots)$ \\
\hline Junio & 54 & $a(\ldots)$ & 1 & 6 & $\mathrm{a}(\ldots)$ \\
\hline Julio & 489 & $a(\ldots)$ & 0 & 68 & $a(\ldots)$ \\
\hline Agosto & 92 & $a(\ldots)$ & 0 & 14 & $a(\ldots)$ \\
\hline Septiembre & 118 & $a(\ldots)$ & 2 & 24 & $a(\ldots)$ \\
\hline Octubre & 210 & $a(\ldots)$ & 0 & 38 & $a(\ldots)$ \\
\hline Noviembre & 5.412 & $a(\ldots)$ & 2 & 1.076 & $a(\ldots)$ \\
\hline Diciembre & 0 & $\mathrm{a}(\ldots)$ & 0 & 1.673 & $a(\ldots)$ \\
\hline Total, 2005 & 6.891 & 26,6 & 11 & 2.931 & 50 \\
\hline Enero & 10 & $\mathrm{a}(\ldots)$ & 2 & 3 & $\mathrm{a}(\ldots)$ \\
\hline Febrero & 54 & $a(\ldots)$ & 3 & 4 & $a(\ldots)$ \\
\hline Marzo & 89 & $a(\ldots)$ & 4 & 10 & $a(\ldots)$ \\
\hline Abril & 416 & $a(\ldots)$ & 4 & 38 & $a(\ldots)$ \\
\hline Mayo & 91 & $a(\ldots)$ & 2 & 12 & $a(\ldots)$ \\
\hline Junio & 1.156 & $\mathrm{a}(\ldots)$ & 6 & 195 & $a(\ldots)$ \\
\hline Julio & 1.137 & $a(\ldots)$ & 4 & 93 & $a(\ldots)$ \\
\hline Agosto & 74 & $\mathrm{a}(\ldots)$ & 6 & 6 & ${ }^{a}(\ldots)$ \\
\hline Septiembre & 12 & $a(\ldots)$ & 6 & 2 & ${ }^{a}(\ldots)$ \\
\hline Octubre & 182 & $\mathrm{a}(\ldots)$ & 10 & 21 & ${ }^{a}(\ldots)$ \\
\hline Noviembre & 5.555 & $\mathrm{a}(\ldots)$ & 48 & 1.133 & ${ }^{a}(\ldots)$ \\
\hline Diciembre & 9972 & ${ }^{a}(\ldots)$ & 33 & 1.928 & ${ }^{a}(\ldots)$ \\
\hline Total, 2006 & 18.748 & 72,3 & 128 & 3.445 & 58.7 \\
\hline Enero & 4.146 & $\mathrm{a}(\ldots)$ & 22 & 810 & $\mathrm{a}(\ldots)$ \\
\hline Febrero & 6.817 & $\mathrm{a}(\ldots)$ & 13 & 1.283 & ${ }^{a}(\ldots)$ \\
\hline Marzo & 541 & $\mathrm{a}(\ldots)$ & 18 & 102 & ${ }^{a}(\ldots)$ \\
\hline Abril & 236 & $\mathrm{a}(\ldots)$ & 10 & 36 & ${ }^{a}(\ldots)$ \\
\hline Mayo & 477 & ${ }^{a}(\ldots)$ & 12 & 104 & ${ }^{a}(\ldots)$ \\
\hline Junio & 360 & $\mathrm{a}(\ldots)$ & 0 & 75 & $\mathrm{a}(\ldots)$ \\
\hline Julio & 127 & $\mathrm{a}(\ldots)$ & 3 & 47 & $a(\ldots)$ \\
\hline Agosto & 440 & $\mathrm{a}(\ldots)$ & 2 & 100 & ${ }^{\mathrm{a}}(\ldots)$ \\
\hline Septiembre & 258 & $a(\ldots)$ & 5 & 72 & $a(\ldots)$ \\
\hline Octubre & 20.083 & $a(\ldots)$ & 4 & 3081 & $\mathrm{a}(\ldots)$ \\
\hline Noviembre & 3.764 & ${ }^{a}(\ldots)$ & 11 & 909 & ${ }^{a}(\ldots)$ \\
\hline Total, 2007 & 37.249 & 100 & 100 & 6.619 & 100 \\
\hline Enero 2008 & 459 & $\mathrm{a}(\ldots)$ & 0 & 94 & $\mathrm{a}(\ldots)$ \\
\hline
\end{tabular}

a (...): no determinado. 
más deprimidas del distrito de Santa Marta, con las características mencionadas anteriormente, y un gran porcentaje de sus pobladores son desplazados por la violencia de otras partes del departamento.

\section{Descripción de los casos de rabia humana}

Con el propósito de facilitar el seguimiento de los casos, se les asignó un número de acuerdo con el orden cronológico en que fueron captados por el sistema de vigilancia. Los casos de rabia humana correspondieron a los números 5,10 , 18 y 21 (cuadro 1).

Caso 5. Era un paciente de 29 años de edad, de sexo masculino, con inicio de los síntomas el 26 de octubre de 2006 y reporte de haber sufrido una agresión en el labio superior por una perra de raza dálmata el 26 de septiembre del mismo año.

Los síntomas se iniciaron con dolor de garganta, inapetencia, malestar general, fiebre y ansiedad. Posteriormente, presentó agresividad e intento de suicidio y, por último, parálisis de los miembros inferiores, salivación y eyaculación espontánea. El paciente falleció el 5 de noviembre de 2006.

Caso 10. Era un paciente de 14 años de edad, de sexo masculino, con inicio de los síntomas el 20 de noviembre de 2006 y reporte de haber sufrido una escoriación en el pie izquierdo al patear a una perra de raza dálmata en el hocico, aproximadamente, dos meses antes. Se estableció que la perra involucrada en los casos 5 y 10 fue la misma.

Los síntomas se iniciaron con calambres y dolor en la pierna izquierda, fiebre, escalofríos, cefalea y ansiedad, seguidos de sialorrea, hidrofobia, aerofobia y dificultad respiratoria. Finalmente, presentó mirada extraviada, sed, rigidez de nuca, contracturas musculares ocasionales involuntarias, fascies de terror con apertura ocular extrema, midriasis bilateral y parálisis de las cuatro extremidades. El paciente falleció el 25 de noviembre de 2006.

Caso 18. Era un paciente de 20 años de edad, de sexo masculino, con inicio de los síntomas el 5 de enero de 2007 y reporte de haber sufrido una agresión leve en el brazo derecho por un perro callejero, aproximadamente, tres meses antes.

Los síntomas se iniciaron con dolor abdominal de moderada intensidad, vómito y diarrea. Posteriormente, presentó parálisis total de las cuatro extremidades y convulsiones. El paciente falleció el 16 de enero de 2007.

Caso 21. Era un paciente de 3 años de edad, de sexo masculino, con inicio de los síntomas el 13 de enero de 2007 y con reporte de haber sido agredido por un perro callejero, el cual le causó una herida leve en un brazo, aproximadamente, dos meses antes.

Los síntomas se iniciaron con dificultad para sostenerse en las piernas. Posteriormente, presentó fiebre, convulsiones y agresividad, y finalmente, parálisis de las cuatro extremidades y coma. El paciente falleció el 27 de enero de 2007.

\section{Diagnóstico y tipificación antigénica del virus}

Se confirmó post mórtem la infección por virus de la rabia en 27 perros, en los cuales se detectó antígeno rábico IFD en tejido encefálico. Además, se confirmó el caso 3 de rabia en perro por nexo epidemiológico (la perra dálmata que ocasionó las dos primeras muertes humanas, casos 5 y 10), para un total de 28 casos confirmados de rabia en perros en el presente estudio.

De igual manera, se confirmó infección por virus de la rabia en cuatro personas, en quienes se detectó antígeno rábico en tejido encefálico por técnicas de inmunohistoquímica e histopatología, en los casos 5, 10, 18 y 21, e IFD y prueba biológica por inoculación en ratones de laboratorio, en los casos 10, 18 y 21 (cuadro 1).

Los cerebros de los casos humanos estudiados por histopatología e inmunohistoquímica mostraban macroscópicamente un importante grado de edema y de congestión, correspondiente a encefalitis de predominio diencefalomesencefálico. El componente inflamatorio fue particularmente importante hacia la región hipotalámica, principalmente, en la franja vecina a la cubierta del 
epéndimo del tercer ventrículo y en cortes de la parte superior del mesencéfalo, con presencia de micronódulos gliales tipo Babes, fenómenos de satelitosis y neuronofagia. Los corpúsculos de Negri fueron muy abundantes en todos los niveles $\mathrm{y}$, particularmente, en el lóbulo temporal en el asta de Ammón y el cerebelo. Se observó antígeno viral rábico en notoria proporción en todo el encéfalo. El caso 5 humano presentó moderada hernia simétrica tanto del uncus del hipocampo, como de las amígdalas del cerebelo, e internamente, los núcleos centrales no mostraron alteraciones morfológicas como tampoco en los cortes del tallo cerebral. Se aisló la variante antigénica 1 , típica de rabia transmitida por perros, como la única variante presente en el material encefálico de los casos de rabia en 27 perros y 3 humanos. No fue posible aislar los virus del caso humano 5 , debido a que el tejido encefálico fue conservado en formol, lo cual imposibilitó el procedimiento.

\section{Vacunación de perros y gatos}

Los datos de la vacunación y coberturas de vacunación en perros y gatos, así como los de eliminación de perros en el distrito de Santa Marta en el periodo 2005-2008 (enero), se muestran en el cuadro 2. Las coberturas de la vacunación en perros y gatos corresponden al porcentaje de animales que fueron vacunados en cada mes y año, teniendo como el $100 \%$ al número total de animales según el censo 2007, con el cual se estimaron las poblaciones caninas y felinas del distrito de Santa Marta en 25.925 y 5.871 , respectivamente.

En 2005, el número de perros y gatos vacunados fue de 6.891 y 2.931, correspondientes a coberturas anuales de vacunación de $26,6 \%$ y $50 \%$, respectivamente. Entre enero y abril de 2006 (antes del registro del primer caso de rabia canina), se vacunaron 569 perros y 55 gatos que corresponden a coberturas de vacunación de $2,2 \%$ y $0,4 \%$, respectivamente. Los programas de vacunación masiva de perros y gatos tuvieron lugar en noviembre de 2006 y febrero de 2007, con 26.490 dosis aplicadas a perros y 5.154 aplicadas a gatos, que corresponden a coberturas de vacunación superiores al
$100 \%$ en perros y $88 \%$ en gatos. Una segunda campaña de vacunación masiva tuvo lugar en octubre y noviembre de 2007, con 23.847 dosis aplicadas a perros y 3.990 aplicadas a gatos, que correspondentes a coberturas de vacunación de $92 \%$ en perros y $68 \%$ en gatos.

\section{Medición del nivel de anticuerpos antirrábicos neutralizantes en los perros vacunados}

Se comprobó seropositividad en $77 \%$ de los perros de la muestra. Sin embargo, sólo se detectó seroconversión de anticuerpos neutralizantes contra la rabia superior o igual a $0,5 \mathrm{UI} / \mathrm{ml}$ en suero (tomado como indicativo de una adecuada respuesta humoral a la vacunación y de protección serológica contra la enfermedad) en $47 \%$. La distribución de los valores de concentración de los anticuerpos antirrábicos no se ajustó a una curva normal según la prueba Kolmogorov-Smirnov; por lo tanto, en el análisis estadístico se utilizaron pruebas no paramétricas (prueba $U$ de MannWhitney y prueba post hoc-Scheffé) para determinar diferencias de las medianas entre las agrupaciones de perros por sexo y comuna.

Al agrupar los perros seropositivos de la muestra por rangos de concentración de anticuerpos antirrábicos neutralizantes, se obtuvo que el mayor porcentaje de perros (29\%) estuvo entre 0,1 y $0,49 \mathrm{UI} / \mathrm{ml}$, seguido del $17 \%$ entre 0,5 y $0,99 \mathrm{Ul} / \mathrm{ml}, 14 \%$ entre 1,0 y $1,99,5 \%$ entre 2,0 y $2,99 \mathrm{Ul} / \mathrm{ml}$ y $1 \%$ entre 3,0 y $3,99 \mathrm{Ul} / \mathrm{ml}$. El $53 \%$ de las hembras presentaron protección serológica, mientras que este indicador en machos fue de $43 \%$.

Por regresión logística, esta diferencia no fue significativa $(p=0,112)$, como tampoco lo fueron las diferencias de las medianas de los valores de anticuerpos antirrábicos entre machos $(0,42$ $\mathrm{UI} / \mathrm{ml})$ y hembras $(0,53 \mathrm{UI} / \mathrm{ml})(p=0,134$-prueba $U$ de Mann-Whitney), ni entre las comunas del distrito ( $p=0,938$, prueba post hoc-Scheffé). Por regresión logística, se determinaron diferencias significativas entre los porcentajes de perros con protección serológica entre las comunas del distrito $(p=0,003)$ (figura 3$)$. Así, las comunas 1 y 2 presentaron los porcentajes de protección más bajos, $27 \%$ y $29 \%$ respectivamente, mientras 
que las comunas 9 y 10 presentaron los más altos, $70 \%$ y $80 \%$ respectivamente.

\section{Discusión}

Se describe el brote de rabia urbana de mayor magnitud reportado en ciudades de Colombia, según los datos oficiales del Ministerio de la Protección Social de Colombia, y las acciones de control de foco utilizadas. Cuatro humanos y 28 perros fueron confirmados como positivos para rabia, para los cuales únicamente la variante antigénica 1 fue aislada, lo cual indica que los virus transmitidos tuvieron origen canino.

Estudios previos han demostrado la transmisión en Colombia de las variantes antigénicas 1 de perro, 3 y 5 de murciélagos hematófagos, 4 de murciélagos insectívoros, 8 de zorro y, además, variantes antigénicas no clasificadas que son transmitidas por murciélagos insectívoros (17). En el Magdalena, la variante antigénica 1 ha sido aislada exclusivamente de perros y zorros, y la variante antigénica 3 , en gatos y bovinos, lo que demuestra nuevamente el fenómeno de independencia en la transmisión de la rabia entre especies domésticas cercanas entre sí, como son los gatos y los perros, que se ha observado en Colombia y el resto de países en Latinoamérica.

De hecho, durante el periodo que duró el brote descrito en este artículo, ningún gato del distrito

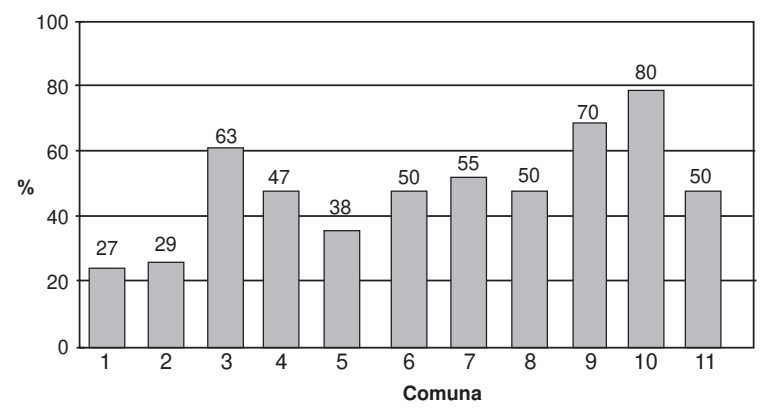

Figura 3. Porcentaje de protección serológica contra la rabia por comunas en el distrito de Santa Marta, Colombia, 2007. Diagrama de barras que muestra los porcentajes de protección serológica contra la rabia como resultado de las campañas de vacunación canina en las 11 comunas del distrito de Santa Marta, Colombia 2007. Las diferencias son estadísticamente significativas ( $p=0,003$ según la prueba de regresión logística). de Santa Marta resultó contagiado con rabia. El brote descrito en este estudio tuvo sus primeros casos en la comuna 6, ubicada en el nororiente del distrito de Santa Marta; posteriormente, la transmisión del virus tuvo lugar en las comunas 3 y 4, ubicadas hacia el noroccidente. Finalmente, la transmisión del virus se trasladó con dirección sur a las comunas 1,7 y 8 , ubicadas en el centro y sur del distrito, respectivamente, y hacia las comunas 10 y 11, ubicadas en áreas rurales (figura 1).

El número real de casos de rabia ocurridos durante el brote se desconoce. Posiblemente existieron casos de rabia, especialmente en perros, que no fueron diagnosticados debido a que no fueron detectados por el sistema de vigilancia epidemiológica local. Esta hipótesis se apoya en el hecho de que, durante el brote, existieron silencios epidemiológicos de hasta cinco meses (figura 2), en los cuales, a pesar de existir transmisión del virus rábico, ningún perro fue diagnosticado como positivo para infección rábica. Lo anterior resalta la fundamental importancia que tiene el mantener una vigilancia activa y sólida, que cubra todos los sectores en la ciudad, con un mínimo de perros muestreados que corresponda al $0,1 \%$ del total de la población canina censada (29), con el fin de ofrecer cifras ajustadas a la realidad en cuanto a la casuística y caracterización de la verdadera magnitud de un brote.

El estudio del material encefálico de los cuatro casos humanos reveló que la localización anatómica de las lesiones en el cerebro, especialmente el compromiso inflamatorio del hipotálamo, explican algunas manifestaciones neuropsiquiátricas observadas en casos de rabia humana furiosa. En contraste, la rabia humana con paresia o paralítica, la cual es transmitida por murciélagos hematófagos, produce lesiones que se ubican predominantemente en las áreas motoras del tallo cerebral y del segmento medular C1 (30).

En ninguno de los casos humanos del presente estudio, se observó correlación clara entre el lugar anatómico de inoculación del virus rábico y el periodo de incubación de la enfermedad. 
Como respuesta a la vacunación, se observó una respuesta inmune humoral antirrábica en $77 \%$ de los perros de la muestra estudiada. Únicamente $47 \%$ de los perros estudiados presentaron protección serológica contra la rabia, definida por concentraciones de anticuerpos neutralizantes en suero iguales o superiores a $0,5 \mathrm{Ul} / \mathrm{ml}$.

Este porcentaje, aunque bajo, podría corresponder a lo esperado en condiciones de campo, si se tienen en cuenta algunos factores moduladores de la respuesta inmune humoral en los perros, como: a) que la población habría recibido la primera dosis de vacuna antirrábica sin haber sido vacunada anteriormente; b) desnutrición y presencia de ectoparásitos y endoparásitos; c) fallas técnicas generadas por entrenamiento insuficiente del personal encargado de la vacunación; d) rompimiento de la cadena de frío de los biológicos, y e) falta de mantenimiento en la vacunación sistemática.

Se ha reportado protección serológica contra la rabia, producto de campañas masivas de vacunación canina, en Brasil, Perú, España, Túnez y Japón, y se encontraron entre $34 \%$ y $77 \%$ de perros protegidos (con concentración de anticuerpos neutralizantes de $0,5 \mathrm{UI} / \mathrm{ml}$ y superiores) (31-34). Existe un solo reporte de protección serológica contra la rabia en casi la totalidad (97\%) de los perros vacunados después de una campaña (35).

En el presente estudio no se observaron tendencias de la respuesta inmune humoral de los perros asociada al sexo, pero sí se encontraron diferencias estadísticamente significativas asociadas a las comunas del distrito. Al respecto, las comunas 1 y 2 presentaron los porcentajes más bajos de protección, $27 \%$ y $28 \%$, respectivamente, mientras que las comunas 9 y 10 presentaron los porcentajes más altos de protección, $70 \%$ y $80 \%$, respectivamente; se desconocen las causas de estas diferencias (figura 3 ).

En este artículo se muestra el riesgo que puede llegar a tener la reducción o suspensión de las campañas de vacunación antirrábica sobre la salud pública, principalmente en grandes ciudades, lo anterior teniendo en cuenta que en el 2005, antes de la iniciación del brote, la cobertura de vacunación en el distrito de Santa Marta fue de sólo 26,6\%. Este porcentaje de cobertura de vacunación no resultó útil para prevenir la transmisión del virus de la rabia entre los perros del distrito, y más aun cuando el distrito de Santa Marta presentaba el riesgo de introducción el virus de la rabia transmitida por perros, considerando que por más de una década el departamento del Magdalena ha presentado casos de rabia, con altas tasas de transmisión en los municipios de Ciénaga, Pivijay, la Zona Bananera, Fundación, y Aracataca. En el periodo 2000-2006, estos municipios presentaron 15, $17,16,10$ y 6 casos confirmados de rabia en perros, todos con la variante antigénica 1 típica de la rabia de origen canino (no se presentan los datos en este estudio. Laboratorio de Virología, Instituto Nacional de Salud, Bogotá, D.C.). El departamento de Magdalena ha sido el único departamento de Colombia con circulación de virus rábico transmitido por perros durante los últimos 10 años.

Por todo lo anterior, se especula que el brote de rabia en el distrito de Santa Marta pudo haberse iniciado por importación del virus desde algún municipio vecino, o por contacto entre perros y zorros infectados con rabia que habitan en cercanías de la Sierra Nevada, hipótesis que es apoyada por los datos de tipificación viral (11).

Nuestro estudio resalta la gran importancia que tiene el mantener adecuadas coberturas de vacunación, que alcancen como mínimo al $80 \%$ de los perros, año tras año, aun cuando existan silencios epidemiológicos prolongados, como en el caso del distrito de Santa Marta que fue superior a los 20 años; el último caso de rabia canina en el distrito fue confirmado en 1985.

Los datos de nuestro trabajo muestran, además, el impacto que tienen las campañas de vacunación y revacunación intensivas sobre la reducción en el número de casos de un brote de rabia urbana, como el reportado en el presente trabajo. A este respecto, nuestros datos indican que, a pesar de haber iniciado intensas campañas de vacunación y revacunación canina simultáneas a la presentación de la fase aguda del brote (figura 2), su control definitivo se logró, aproximadamente, 
20 meses después de reportado el inicio del brote, y 14 meses después de haberse iniciado las campañas masivas de vacunación. Esto da una idea del periodo tan prolongado en que la población humana permaneció en riesgo y de la complejidad que presenta la eliminación de un brote de rabia en una ciudad, aun cuando el transmisor sea exclusivamente el perro.

De lo anterior se concluye la fundamental importancia que tiene el iniciar oportunamente las intensas campañas de vacunación, en el momento en que ocurre el primer caso de rabia canina, principalmente en un asentamiento urbano en donde perros y humanos se encuentran en permanente contacto. En este sentido, es importante mejorar la capacidad y oportunidad de reacción de los organismos de salud en Colombia en respuesta ante un caso de rabia en las ciudades y municipios.

Dados varios factores, como el que la transmisión del virus de la rabia puede no haber sido interrumpida totalmente en el distrito de Santa Marta en la actualidad y que la cercanía de zorros rabiosos de la Sierra Nevada de Santa Marta favorece un permanente contacto entre éstos y los perros del distrito, además de que el porcentaje de protección serológica contra la rabia se encontró inferior al $50 \%$ en la población canina en este estudio, se hace obligatorio mantener campañas anuales de revacunación y hacer mantenimiento continuo de vacunación de cachorros; esto con el fin de incrementar el porcentaje de perros protegidos y reducir el de perros susceptibles, como se ha observado en anteriores estudios (36) y así lograr el control total del brote de rabia urbana. Hacia el futuro, las mencionadas campañas anuales de vacunación y revacunación tendrán que continuar llevándose a cabo mientras la rabia transmitida por perros permanezca endémica en el departamento de Magdalena.

\section{Agradecimientos}

Los autores del presente estudio desean agradecer de manera especial a Nasly Goenaga Cárdenas, profesional en epidemiología, adscrita a la Secretaría de Salud Distrital de Santa Marta, por su decidida colaboración y apoyo a las acciones de prevención y control de foco durante las fases iniciales del brote de rabia.

\section{Conflicto de intereses}

Los autores del artículo hacen constar que no existe, de manera directa o indirecta, ningún tipo de conflicto de intereses financieros, académicos o personales que puedan poner en peligro la validez de la investigación.

\section{Financiación}

Los recursos económicos necesarios para el trabajo de campo y de laboratorio fueron aportados por el Instituto Nacional de Salud, la Secretaría de Salud del Distrito de Santa Marta y el Ministerio de la Protección Social.

\section{Referencias}

1. Beran GW, Steele JH. Handbook of zoonoses. Section B: Boca Ratón, FI: CRC Press; 1994. p. 307.

2. Wunner WH, Larson JK, Dietzchold B, Smith CL. The molecular biology of rabies virus. Rev Infect Dis. 1988;10(Suppl.4):771-84.

3. Tordo N, Kouknetzoff A. The rabies virus genome: an overview. Onderstepoort J Vet Res. 1993;60:263-9.

4. Bourhy H, Kissi B, Audry L, Smreczak M, SadkowskaTodys M, Kulonen K, et al. Ecology and evolution of rabies virus in Europe. J Gen Virol. 1999;80:2545-57.

5. Guerra MA, Curns AT, Rupprecht CE, Hanlon CA, Krebs JW, Childs JE. Skunk and raccoon rabies in the eastern United States: temporal and spatial analysis. Emerg Infect Dis. 2003;9:1143-50.

6. Nel L, Jacobs J, Jaftha J, Meredith C. Natural spillover of a distinctly Canidae-associated biotype of rabies virus into an expanded wildlife host range in southern Africa. Virus Genes. 1997;15:79-82.

7. Sabeta CT, Bingham J, Nel LH. Molecular epidemiology of canid rabies in Zimbabwe and South Africa. Virus Res. 2003;91:203-11.

8. Johnson N, Black C, Smith J, Un H, McElhinney LM, Aylan O, et al. Rabies emergence among foxes in Turkey. J Wildl Dis. 2003;39:262-70.

9. Krebs JW, Williams SM, Smith JS, Rupprecht CE, Childs JE. Rabies among infrequently reported mammalian carnivores in United States, 1960-2000. J Wildl Dis. 2003;39:253-61.

10. Stankov S. Typing of field rabies virus strains in FR Yugoslavia by limited sequence analysis and monoclonal antibodies. Med Pregl. 2001;54:446-52.

11. Páez A, Saad C, Núñez C, Boshell J. Molecular epidemiology of rabies in northern Colombia 1994-2003: 
Evidence for human and fox rabies associated with dogs. Epidemiol Infect. 2005;133:529-36.

12. Ministerio de Salud, Instituto Nacional de Salud. Rabia. Serie de notas e informes técnicos. Quinta edición. Bogotá, D.C.: Minsalud-INS: 1995.

13. Rico A, Díaz A, Rico E. Informe de la rabia urbana en Colombia, 1996-2001. Programa de Zoonosis. Bogotá D.C.: Ministerio de Salud: 2001.

14. Páez A, Núñez C, García C, Boshell J. Molecular epidemiology of rabies epizootics in Colombia: evidence for human and dog rabies associated with bats. J Gen Virol. 2003;84:795-802.

15. Páez A, Núñez C, García C, Boshell J. Epidemiología molecular de epizootias de rabia en Colombia 19942002. Evidencia de rabia humana y canina asociada a quirópteros. Biomédica. 2003;23:19-30.

16. Hughes GJ, Páez A, Boshell J, Rupprecht CE. A phylogenetic reconstruction of the epidemiological history of canine rabies virus variants in Colombia. Infect Gen Evol. 2004;4:45-51.

17. Páez A, Velasco-Villa A, Rey G, Rupprecht C. Molecular epidemiology of rabies in Colombia 19942005 based on partial nucleoprotein gene sequences. Virus Res. 2007;130:172-81.

18. Ministerio de la Protección Social. Resolución 002921 de junio 25 de 2007. Declaración de emergencia sanitaria por brote de rabia humana transmitida por caninos y desabastecimiento de vacunas y sueros antirábicos en el Distrito de Santa Marta, Colombia. Bogotá, D.C.: Ministerio de la Protección Social; 2007.

19. McQueen JL, Lewis AL, Schneider NJ. Rabies diagnosis by fluorescent antibody. Its evaluation in a public health laboratory. Am J Public Health. 1960;50:1743-52.

20. Meslin FX, Kaplan MM, Koprowski H. The mouse inoculation test (Chapter 6), and The fluorescent antibody test (Chapter 7). In: World Health Organization. Laboratory techniques in rabies. Fourth edition. Geneva: World Health Organization; 1996.

21. Rodríguez G. Diagnóstico inmunológico del virus de la rabia en tejido incluido en parafina. Inf Quinc Epidemiol Nac. 1997;16:235-6.

22. Koprowski H. Prueba de inoculación en ratones. En: Organización Mundial de la Salud. Técnicas de laboratorio aplicadas a la rabia. Washington D.C.: OPS/ OMS; 1956. p. 57-69.

23. Dietzschold B, Rupprecht CE, Tollis M, Lafon M, Mattel J, Wiktor TJ, et al. Antigenic diversity of the glycoprotein and nucleocapsid proteins of rabies and rabies related viruses: implications for epidemiology and control of rabies. Rev Infect Dis. 1988;10(Suppl.4):785-98.
24. Ministerio de Salud, Instituto Nacional de Salud. Rabia. Guía práctica para la atención integral de personas agredidas por un animal potencialmente transmisor de rabia. Serie de notas e informes técnicos No. 4. Sexta edición. Bogotá, D.C.: Ministerio de SaludINS: 2002.

25. Scheffé H. Statistical inference in the non-parametric case. Ann Math Statist. 1943;14:305-32.

26. Kolmogorov A. Confidence limits for an unknown distribution function. Ann Math Statist. 1941;12:461-3.

27. Smirnov NV. Table for estimating the goodness of fit of empirical distributions. Ann Math Statist. 1948;19:27981.

28. Mann HB, Whitney DR. On a test of whether one or two random variables is stochastically larger than the other. Ann Math Statist. 1947;18:50-60.

29. Schneider MC. Estudo de avaliação sobre área de risco para a raiva no Brasil. Rio de Janeiro, 1990 (Dissertação de Mestrado). Rio de Janeiro: Escola Nacional de Saúde Pública da Fundação Oswaldo Cruz; 1990.

30. Valderrama J, García I, Figueroa G, Rico E, Sanabria J, Rocha N, et al. Brotes de rabia humana transmitida por vampiros en los municipios de Bajo y Alto Baudó, departamento del Chocó, Colombia 2004-2005. Biomédica. 2006;26:387-96.

31. Delgado S, Carmenes P. Immune response following a vaccination campaign against rabies in dogs from northwestern Spain. Rev Vet Med. 1997;31:257-61.

32. Shimazaki Y, Inoue S, Takahashi C, Gamoh K, Etoh M, Kamiyama T, et al. Immune response to Japanese rabies vaccine in domestic dogs. J Vet Med B Infect Dis Vet Public Health. 2003;50:95-8.

33. Rigo L, Honer MR. Titulacao de anticorpo contra o virus de raiva em caes, em Campo Grande, MS na Campanha Anti-rábica de 2003. Rev Soc Bras Med Trop. 2006;39:553-5.

34. López R, Díaz A, Condori E. Susceptibilidad canina a rabia después de una campaña de vacunación en zonas endémicas del Perú. Revista Peruana de Medicina Experimental y Salud Pública. 2007;24:13-9.

35. Chomel B, Chappuis G, Bullón F, Cárdenas E, de Beublain TD, Lombard M, et al. Mass vaccination campaign against rabies: are dogs correctly protected? The Peruvian experience. Rev Infect Dis. 1988;10(Suppl.4):697-702.

36. Seghaier C, Cliquet F, Hammami S, Aouina T, Aubert M. Rabies mass vaccination campaigns in Tunisia: are vaccinated dogs correctly immunized? Am J Trop Med Hyg. 1999;61:879-84. 